\title{
Mortality Decline in Kenya: A Reexamination of Recent Under-Five Mortality Estimate
}

\author{
George Odwe, ${ }^{1}$ Anne Khasakhala, ${ }^{1}$ Titus Agwanda, ${ }^{1}$ Andrew Imbwaga, ${ }^{2}$ and Zena Lyaga ${ }^{1}$ \\ ${ }^{1}$ University of Nairobi, P.O. Box 30197, Nairobi 00100, Kenya \\ ${ }^{2}$ Kenya National Bureau of Statistics, P.O. Box 30266, Nairobi 00100, Kenya \\ Correspondence should be addressed to George Odwe; godweus@yahoo.com
}

Received 28 January 2015; Revised 15 June 2015; Accepted 18 June 2015

Academic Editor: Pranitha Maharaj

Copyright (c) 2015 George Odwe et al. This is an open access article distributed under the Creative Commons Attribution License, which permits unrestricted use, distribution, and reproduction in any medium, provided the original work is properly cited.

\begin{abstract}
This study examined the extent of birth displacement and its effect on the under-five mortality estimates in Kenya. Using data from 2003 and 2008/09 Kenya Demographic and Health Surveys, we evaluate the variability of birth displacement by region and place of residence based on the survival status of the child. We compute birth ratios for children born in the 5 th calendar year preceding each survey and note the possible effect on under-five mortality estimates. Results show that under-five mortality estimates in 2008/09 survey are smaller than that of a similar period in 2003 survey by 17 percent. Overall, birth ratios for the 5th calendar year were below 100 percent suggesting presence of birth displacement. However, there was no variance in the displacement between surviving and dead children, hence modest impact on the under-five mortality rate. Evidence suggests that the remarkable decline in the underfive mortality rate recorded in 2008/09 is a function of both overestimation of mortality rate in 2003 survey and underestimation in 2008/09 survey. We recommend that data from more than one source be used to interpret under-five mortality decline and further research should be conducted linking the observed mortality decline to the delivery of known effective interventions.
\end{abstract}

\section{Introduction}

Kenya enjoyed a rather impressive and sustained decline in the under-five mortality rate (sum of all deaths that occur to children who were born alive but did not survive until their fifth birthday) of 3 percent to 4 percent per annum during the period from 1965 to 1980 [1]. The decline was almost twice the rate of the average country of Sub-Saharan Africa during this period. However, the decline was slowed to about 2 percent in the 1980s. The 1998 Kenya Demographic and Health Survey (KDHS) provided the first clear evidence that the decline not only had slowed but also had been reversed during the 1990s [2]. Data obtained from birth histories indicated a 24 percent increase in the under-five mortality rate from the mid1980 s to the mid-1990s with enormous regional differentials. However, the 2008/9 KDHS showed a reversal in the levels and differentials of under-five mortality rate during the 1990s and early 2000 . The under-five mortality rate for five-year periods preceding the survey declined by 36 percent from 115 deaths per 1000 to 74 deaths per 1000 . Infant mortality declined by 32 percent during the same period [3]. For the first time infant mortality (deaths that occur before the first year of life) was higher in urban areas compared to rural areas while infants for mothers with no education were less likely to die compared to women with some slight primary level of education. The remarkable decline in the observed level of childhood mortality rates was widely attributed to the efforts by the government to improve health services [4]. Nevertheless, questions emerge from these observations on whether the observed rapid change in under-five mortality patterns is an artifact of data or a result of changes in the factors influencing mortality regimes.

These questions raise another important issue on whether the remarkable decline in under-five mortality in Kenya was real. The substantial decline in the levels of childhood mortality reported in 2008/9 KDHS requires further scrutiny to establish the reliability of the mortality estimates. Accurate measurement of under-five mortality rate is fundamental as an indicator of population health and has always been used to track development progress of a country $[5,6]$. Indeed major health programmes and initiatives are centered on under- 5 
mortality. The UN Millennium Development Goals (MDG) agreed by most UN member states in 2000 set a target of reducing the under- 5 mortality rate by two-thirds by 2015 . The probability of dying before age 5 denoted by ${ }_{5} q_{0}$ is an important input parameter in the computation of mortality indicators such as life expectancy for developing countries without reliable vital registration system such as Kenya.

Given that Kenya still lacks reliable vital registration system, the childhood mortality estimates are largely derived from the Demographic and Health Survey (DHS). The DHS calculates the under-five mortality from retrospective reproductive histories information as reported by female respondents aged 15-49 years [7]. As a result, DHS is prone to sampling and coverage errors especially on the data on dates which could affect fertility and mortality estimates. This study examines whether the remarkable decline in underfive mortality in Kenya recorded in 2008/09 KDHS is real or an artifact of measurement. We compare the extent of birth displacement and its effect on under-five mortality rate by socioeconomic characteristics (place of residence and region) using 2003 and 2008/09 Kenya DHSs. There is a possibility that either the most recent survey underestimated the level of under-five mortality or the previous survey overestimated the level of under-five mortality. Research evidence shows that the observed change in mortality levels can result from three major sources: change in mortality determinants [8], effects arising from data collection process [9], and estimation biases due to effects of HIV and AIDS [10, 11].

Mortality levels can change rapidly when there are improvements in health status and health care, particularly in maternal and child health services $[8,12]$, if there are changes in health-seeking behaviour and improvements in the delivery of health services $[13,14]$. More service delivery points, education of the general population on the utilization of services, and actual utilization of services have the potential of reducing mortality rate within a short span of time. Increasing utilization of antenatal care (ANC) and skilled delivery services may drastically reduce neonatal and postneonatal deaths while immunization can reduce childhood mortality.

The observed mortality decline may be an artifact of data $[15,16]$. There may be no real change in mortality levels; however, data collection process may result in statistics that show that mortality has declined. The deficiencies of Demographic Health Survey (DHS) have been well recognized. Statistics of the children population are prone to the usual coverage errors and the potential sources of bias include age misstatement, underreporting of births and deaths $[17,18]$. The reliability of the mortality measurement is affected by the accuracy and completeness of information on births and deaths.

As noted by Pullum and Becker [17], births can be omitted for a variety of reasons, either deliberately or by accident majorly due to the length of the health module questionnaire. The former reason occurs when there are incentives for interviewers and/or respondents to omit these births. The obvious incentive for an interviewer to omit births is to reduce his/her workload. DHSs have two health questionnaire modules that collect information on antenatal, delivery, and postnatal care of the mother for recent births and health and nutrition question for every child born. Field staffs are required to administer these modules to every birth that occurred in the reference period (usually set to January of the third or fifth complete calendar year prior to a survey). This often leads to a lengthy battery of questions. Interviewers sometimes consider reducing the workload by omitting some events or recording events that occurred within the window period as occurring before the reference date (birth transference). Thus, interviewer gains time by avoiding administration of additional questions meant for births after the reference date. Frequent and systematic birth transference can result in wrong mortality estimates, especially if dead and surviving children are affected differently. Another incentive is to avoid embarrassing questions. Interviewers may feel embarrassed by questions about deceased children and may be more likely to omit deceased children in order to avoid these questions. Deliberate omissions of births may also be due to respondents, who may be reluctant to mention recently deceased children.

Deceased children are more likely to be omitted than surviving children $[7,19]$. The omissions parameters are less often significant among deceased children, because of larger sampling errors, but the average level of omissions is greater among them (15\%) than among surviving children (9\%). This is expected, as it is probably "easier" to omit a deceased child, notably because the child was not listed in the household questionnaire. It is also in line with the idea that people (interviewers, respondents) may be embarrassed by questions about deceased children and may be more likely to omit deceased children [20]. One of the consequences of this result is that child mortality is most probably underestimated in many surveys in Sub-Saharan Africa. Finally, omissions do not vary by gender: about 9 to $10 \%$ of males and females births are omitted on average.

In a recent analysis of demographic surveys in SubSaharan Africa, there is evidence that the DHSs have been underestimating the level of fertility [21, 22]. The trends of fertility generated from consecutive surveys show some indication of omission of births. For example, comparing the most recent survey from the previous survey, underestimation of recent fertility in the first survey can potentially be due to birth displacement and omissions. Overestimation in the second survey can also be due to the displacements of births from earlier periods. Finally, differences in sample implementation can also lead to overestimation or underestimation of fertility in both surveys [7, 23]. For instance, if educated women were accidentally oversampled in the first survey, fertility would be biased downward. Since DHS methodology relies heavily on the birth histories, the effects of omissions and displacements may affect the estimation of not only fertility but also mortality.

Evidence shows that, in countries with generalized epidemics of human immunodeficiency virus (HIV) infection, mortality levels measured from standard statistics based on fertility history may be biased [24-26]. This has been attributed to the correlation between deaths among mothers and early childhood deaths from the acquired immunodeficiency syndrome (AIDS). Empirical data shows that standard cross-sectional survey statistics underestimates true infant 
and under- 5 mortality by $6.7 \%$ and $9.8 \%$, respectively. As noted by Hallett et al. [26], bias is greater when a longer period elapsed before the survey and in later stages of the epidemic and more so if trends are based on data from a single survey. Secondly, the lower the background childhood mortality rates, the greater the biases, since the fraction of HIV-related deaths among children would be higher. Thirdly, higher fertility at older ages would also lead to greater biases because the women infected with HIV at older ages would also be giving birth. A study in 2001 found that HIV prevalence was associated with 25 percent increase in underfive mortality in Kenya between the late 1980s and the mid1990s [1, 27]. Other studies have also linked HIV epidemic to the lack of decline in Kenya's fertility rates experienced during the late 1990s and early 2000, primarily through its associations with elevated child mortality and reduced duration of breastfeeding.

In this paper, we focus on the second aspect of causes of mortality decline. The aim is to examine the extent to which under-five mortality estimates are reliable using 2003 and 2008/9 KDHS datasets. The analysis is focused on the bias due to reporting and survey errors such as displacement of births, omission or nonreporting, and the dates to which these apply by region and place of residence. The study determines the extent of variability in under-five mortality estimates calculated based on $0-4$ and 5-9 and $10-14$ periods in the DHS data.

\section{Materials and Methods}

2.1. Data. The data for this research is drawn from the Kenya Demographic and Health Surveys (KDHSs) of 2003 and 2008/9. KHDSs are collected by means of nationally representative samples of households and are stratified according to regions (provinces). A total of 8,195 and 8,444 women aged 15-49 were interviewed in 2003 and 2008/9, respectively. The DHS collects information on births and survival status in a retrospective manner. Information on birth histories permits direct estimation of age-specific fertility rates (ASFRs) (agespecific fertility rates (ASFRs) are calculated by dividing the number of births to women in a specific age group by the number of woman-years lived during a given period) and the total fertility rate (TFR) (the total fertility rate (TFR) is defined as the average number of children a woman would have if she went through her entire reproductive period, from 15 to 49 years, reproducing at the prevailing ASFRs). Information about the survivorship of children and when they died (if they died) also permits direct estimation of childhood mortality indices (neonatal, postneonatal, infant, child, and under-five mortality rates). The accuracy of events and dates in which these events took place is important for calculation of levels and trends of fertility, infant, and underfive mortality.

2.2. Displacement of Events in Time. The following section presents criteria for identifying birth displacement. As stated previously, there is an incentive for interviewers to reduce their workload by avoiding administering the long and complex maternal and child health sections of the DHS questionnaire for each child born within three or five years before the survey. When this happens, dates of birth of children within the window period tend to be recorded as having occurred before the reference date (i.e., born more than three or more than five years before the survey depending on the reference date chosen). If the displacement of births occurs in frequent and systematic manner, the mortality rate would be affected. Displacement of births beyond the reference date is computed by tabulating the number of births for each year of birth for all children regardless of survival status and then calculating the birth ratio, $B_{x}$ (also known as boundary ratio) $[16,28]$.

Birth displacement means that births are moved from one calendar year to another, for example, 5th calendar year to the 6 th calendar year before the survey date $[7,28]$. It is reported to be motivated by the desire to avoid questions about pregnancy, antenatal care, and immunization. Birth displacement is measured by birth ratios, $B_{x}[9] . B_{x}$ is the number of births reported in the $n$th calendar year before the survey:

$$
B_{x}=\left(\frac{2 \cdot B_{x}}{B_{x-1}+B_{x+1}}\right) \times 100 .
$$

Assuming that births were evenly distributed across years, the ratio would equal 100. A value of less than one hundred implies fewer births than expected for year $x$. The number of births in two adjacent years should be approximately equal, unless birth rates are changing quite dramatically. Ratios under 100 therefore indicate displacement or bias. Table 1 presents the birth ratio.

The last year of eligibility for administering maternal and child health sections is the fifth year preceding the survey for 2003 and 2008/09 KDHS. Hence, only children born within five years preceding the survey were eligible. Applying the birth ratio formula, we have

$$
B_{x}=\frac{2 * B_{5}}{\left(B_{4}+B_{6}\right)} * 100 .
$$

The assumption here is that if there is birth displacement during the 5th and 6th calendar years, then number of births for the 5th year should be smaller than normal year and number of births for the 6th year should be larger than normal year. This implies that $B_{5}$ should be smaller than $B_{4}$ (the normal level) and $B_{6}$ should be larger than $B_{4}$.

\subsection{Comparison of Under-Five Mortality Rate between Two} Surveys. Birth displacement can also be detected by calculating under-five mortality rates in the $0-4$ years, 5-9 years, and 10-14 years prior to the survey. Infant, child, and under-five mortality are calculated using direct and indirect techniques [29]. Whereas the direct methods use data on the date of birth of children, their survival status, and the dates of death or ages at death of deceased children, the indirect methods use information on survival status of children to specific age cohorts of mothers. The DHS uses the former in its reports. Assuming the effects of displacement 
TABLE 1: Birth ratio measurement scale.

\begin{tabular}{|c|c|c|}
\hline Formula & Criteria & Remarks \\
\hline \multirow{3}{*}{$B_{x}=\left(\frac{2 \cdot B_{x}}{B_{x-1}+B_{x+1}}\right) \times 100$} & $B_{x} \geq 95$ & No displacement \\
\hline & $90 \leq B_{x}<95$ & Little birth displacement problem \\
\hline & $B_{x}<90$ & Serious birth displacement \\
\hline
\end{tabular}

TABLE 2: Comparing under-five mortality rate for the $0-4$ period in 2003 and 5-9 period in 2008/09.

\begin{tabular}{lccccccccc}
\hline Period & DHS round & Date & U5M & Period & Round & Date & U5M & U5M difference & U5M relative difference \\
\hline $0-4$ & 1989 & 1986.7 & 90.0 & $5-9$ & 1993 & 1985.9 & 90.0 & 0.0 & 0.0 \\
$0-4$ & 1992 & 1990.9 & 96.0 & $5-9$ & 1997 & 1990.8 & 99.0 & -3.0 & -3.1 \\
$0-4$ & 1998 & 1995.8 & 111.0 & $5-9$ & 2003 & 1995.9 & 110.0 & 1.0 & 0.9 \\
$0-4$ & 2003 & 2000.8 & 115.0 & $5-9$ & $2008 / 9$ & 2000.8 & 95.0 & 20.0 & 17.4 \\
$0-4$ & $2008 / 9$ & 2005.6 & 74.1 & - & - & & - & - & - \\
\hline
\end{tabular}

were uniform among surviving and dead children, then the impact of displacement on mortality estimates would be lacking. However, differential displacement is apparent for mortality estimation by examining the trends in mortality and comparing under-five mortality rates in the $0-4$ years, 5-9 years, and 10-14 years prior to the survey. Comparison between under-five mortality rates estimates for 0-4 and 5-9 periods for two surveys apart (usually 6 or more years) can give an approximate measure of how the $0-4$ period estimate is underestimated due to birth displacement.

To investigate the effect of birth transference in the surveys, new estimates of under-five mortality rate are computed for predefined time periods. The earlier boundary for the last estimation period is set to begin one year before the cutoff in each survey and compared with the actual estimate. If $0-1$ period, $0-2$ period, $0-3$ period, $0-4$ period, and $0-5$ period are used to calculate under-five mortality rate, then under-five mortality rate will be underestimated if there is birth displacement. Comparatively, if $1-5$ period is calculating under-five mortality rate, then under-five mortality rate will be overestimated if there is birth displacement.

\section{Results}

3.1. Mortality Decline. Tables 2 and 3 show under-five mortality rates (U5MR) and child mortality rates (IMR) estimates from 1989-2008/09 Kenya DHSs. We compare the mortality estimates in 0-4-year period for the earlier survey and 59 period for the later survey since these two estimates are exactly referring to the same time point. They should nearly be the same. The relative difference which is defined as $(100 *$ (U5MR1 - U5MR2)/U5MR1) estimates the extent of the differences. Comparing 2003 and 2008/09 KDHS, the underfive mortality rate calculated from the 5-9-year period in $2008 / 9$ is smaller than under-five mortality rate calculated from the $0-4$ period in 2003 by almost 17 percent. Similarly, the infant mortality rate from the 5-9-year period in 2008/9 is smaller than infant mortality rate from the $0-4$ period in 2003 by nearly 13 percent.

Table 4 compares the estimated infant mortality rate and under-five mortality rates for the $0-4$ and 5-9 period prior to the $2003 \mathrm{KDHS}$ to the 5-9 and 10-14 period in the 2008/9 survey. The under-five mortality rate calculated from 5-9year period in 2008/9 is smaller than under-five mortality rates calculated from $0-4$ period in 2003 by about 17 percent while the under-five mortality rate for 5-9 years in 2003 compared to $10-14$ period $2008 / 9$ is smaller by about 16 percent. Similarly, the infant mortality rate calculated from 59-year period in 2008/9 is smaller than infant mortality rate calculated from $0-4$ period in 2003 by about 13 percent while the infant mortality rate for 5-9 years in 2003 compared to 1014 period 2008/9 is smaller by about 19 percent. In the ideal case the estimates should be approximately the same.

3.2. Birth Transference. The cutoff dates for asking the health questions about recent births in the two Kenya surveys were January 1998 (2003 survey) and January 2003 (2008/09 survey). Birth transference occurred in both surveys, resulting in more deceased children recorded as born in the year prior to the health cutoff than in the year after the cutoff (Table 5). The index of birth transference was 1.34 (1158/862) in 2003 and $1.32(1228 / 932)$ in 2008/09.

3.3. Birth Displacement by Survival Status. Table 6 presents the level of birth displacement for all children, surviving children, and deceased children. The analysis is based on the region, place of residence, and the national level. Overall, the birth ratios reported for all children, surviving children, and dead children are below 100 in both 2003 and 2008/9 survey year. This suggests some degree of serious birth displacements. However, there was no variance in the displacement between surviving and dead children. Hence, the overall national mortality estimates may not have been affected by birth displacement.

In contrast, there is evidence of differential in birth ratio place of residence. The result shows that displacement of births among surviving children was higher in urban areas than rural areas in both 2003 and 2008. In addition birth displacement for surviving children and deceased children are both below 82 percent in both urban and rural areas except in 2003 in the urban areas. This clearly demonstrates that the interviewers were displacing births over the line 
TABLE 3: Comparing infant mortality rate for the $0-4$ period in 2003 and 5-9 period in $2008 / 09$.

\begin{tabular}{lccccccccc}
\hline Period & DHS round & Date & IMR & Period & Round & Date & IMR & IMR difference & IMR relative difference \\
\hline $0-4$ & 1989 & 1986.7 & 61 & $5-9$ & 1993 & 1985.9 & 63 & 2.0 & 3.3 \\
$0-4$ & 1992 & 1990.9 & 62 & $5-9$ & 1997 & 1990.8 & 68 & 5.0 & 8.0 \\
$0-4$ & 1998 & 1995.8 & 74 & $5-9$ & 2003 & 1995.9 & 73 & -1.0 & 1.3 \\
$0-4$ & 2003 & 2000.8 & 77 & $5-9$ & $2008 / 9$ & 2000.8 & 67 & -10.0 & 13.0 \\
$0-4$ & $2008 / 9$ & 2005.6 & 52 & - & - & & - & - & - \\
\hline
\end{tabular}

TABLE 4: Comparing U5MR for period 0-4 years prior to earlier survey (2003) to 5-9 and 10-14 in the 2008/9 survey.

\begin{tabular}{lccccccc}
\hline & 2008/9 KDHS & \multicolumn{2}{c}{ 2003 KDHS } & \multicolumn{3}{c}{ Percent difference (2003-2008) } \\
Approximate years & IMR & U5MR & Approximate years IMR U5MR & IMR & U5MR \\
\hline $2004-2008$ & 52 & 74 & - & - & - & - & $13.0 \%$ \\
$1999-2003$ & 67 & 95 & $1998-2003$ & 77 & 115 & $17.3 \%$ \\
$1994-1998$ & 59 & 93 & $1993-1997$ & 73 & 110 & $19.1 \%$ & $15.5 \%$ \\
& & & & 73 & 105 & - & - \\
\hline
\end{tabular}

Note: U5MR: under-five mortality rate, IMR: infant mortality rate.

TABLE 5: Kenya DHS 2003 and 2008/09: births by calendar year.

\begin{tabular}{|c|c|c|c|c|c|}
\hline \multicolumn{3}{|c|}{ Kenya 2003} & \multicolumn{3}{|c|}{ Kenya 2008/09 } \\
\hline Calendar year & Child alive & Child deceased & Calendar year & Child alive & Child deceased \\
\hline 2003 & 1118 & 144 & 2008 & 1247 & 51 \\
\hline 2002 & 1030 & 146 & 2007 & 1119 & 81 \\
\hline 2001 & 1092 & 119 & 2006 & 1147 & 88 \\
\hline 2000 & 995 & 135 & 2005 & 1093 & 67 \\
\hline 1999 & 1013 & 143 & 2004 & 1100 & 86 \\
\hline 1998 & 862 & 124 & 2003 & 932 & 75 \\
\hline 1997 & 1158 & 157 & 2002 & 1228 & 107 \\
\hline 1996 & 861 & 94 & 2001 & 880 & 97 \\
\hline 1995 & 1060 & 139 & 2000 & 1084 & 136 \\
\hline 1994 & 817 & 109 & 1999 & 835 & 111 \\
\hline Index of birth transference & 1.34 & 1.27 & & 1.32 & 1.43 \\
\hline
\end{tabular}

Note: the middle line indicates the date of the cutoff for asking health questions.

TABLE 6: Displacement of events: birth ratios of all births, children alive, and children deceased.

\begin{tabular}{|c|c|c|c|c|c|c|}
\hline \multirow{2}{*}{ Region } & \multicolumn{2}{|c|}{ All children } & \multicolumn{2}{|c|}{ Children alive } & \multicolumn{2}{|c|}{ Children deceased } \\
\hline & 2003 & $2008 / 09$ & 2003 & $2008 / 09$ & 2003 & $2008 / 09$ \\
\hline Kenya & 79.8 & 79.9 & 79.4 & 80.1 & 82.7 & 77.7 \\
\hline \multicolumn{7}{|l|}{ Residence } \\
\hline Urban & 76.2 & 77.3 & 73.2 & 77.0 & 98.7 & 81.0 \\
\hline Rural & 81.0 & 80.6 & 81.6 & 80.9 & 77.3 & 76.8 \\
\hline \multicolumn{7}{|l|}{ Region } \\
\hline Nairobi & 75.5 & 75.3 & 70.6 & 74.3 & 129.4 & 100.0 \\
\hline Central & 81.1 & 101.1 & 82.5 & 104.0 & 60.0 & 54.5 \\
\hline Coast & 91.9 & 71.8 & 90.9 & 74.4 & 97.4 & 48.6 \\
\hline Eastern & 92.1 & 80.4 & 95.1 & 80.5 & 60.9 & 76.9 \\
\hline Nyanza & 74.9 & 99.8 & 74.5 & 100.3 & 76.7 & 96.2 \\
\hline Rift Valley & 74.1 & 75.4 & 73.7 & 74.9 & 78.0 & 83.3 \\
\hline Western & 73.7 & 75.1 & 70.6 & 72.8 & 95.2 & 96.8 \\
\hline $\begin{array}{l}\text { North } \\
\text { Eastern }\end{array}$ & 81.7 & 61.8 & 83.2 & 62.6 & 75.6 & 52.6 \\
\hline
\end{tabular}


TABLE 7: Effect of birth displacement on under-five mortality rate estimate, 2003 KDHS.

\begin{tabular}{|c|c|c|c|c|c|c|}
\hline Age-specific mortality & $0-1$ period & $0-2$ period & $0-3$ period & $0-4$ period & $0-5$ period & $1-5$ period \\
\hline $0-1$ years & 0.0666 & 0.0726 & 0.0729 & 0.0745 & 0.0736 & 0.0755 \\
\hline $1-2$ years & 0.0158 & 0.0152 & 0.0159 & 0.0155 & 0.0138 & 0.0133 \\
\hline 2-3 years & 0.0095 & 0.0086 & 0.0088 & 0.0067 & 0.0093 & 0.0092 \\
\hline 3-4 years & 0.0024 & 0.0037 & 0.0041 & 0.0040 & 0.0047 & 0.0053 \\
\hline $4-5$ years & 0.0024 & 0.0021 & 0.0016 & 0.0023 & 0.0025 & 0.0026 \\
\hline U5MR & 0.0967 & 0.1021 & 0.1033 & 0.1030 & 0.1040 & 0.1059 \\
\hline
\end{tabular}

Published under-five mortality rate $=0.115$.

TABLE 8: Effect of birth displacement on under-five mortality rate estimate by periods, 2008-09 KDHS.

\begin{tabular}{|c|c|c|c|c|c|c|}
\hline Age-specific mortality & 0-1 period & $0-2$ period & $0-3$ period & $0-4$ period & $0-5$ period & $1-5$ period \\
\hline $0-1$ years & 0.0587 & 0.0624 & 0.0576 & 0.0627 & 0.0634 & 0.0647 \\
\hline $1-2$ years & 0.0176 & 0.0139 & 0.0138 & 0.0133 & 0.0139 & 0.0129 \\
\hline 2-3 years & 0.0059 & 0.0061 & 0.0061 & 0.0047 & 0.0062 & 0.0063 \\
\hline 3-4 years & 0.0023 & 0.0024 & 0.0037 & 0.0034 & 0.0035 & 0.0038 \\
\hline 4-5 years & 0.0000 & 0.0012 & 0.0012 & 0.0012 & 0.0017 & 0.0022 \\
\hline U5MR & 0.0845 & 0.0861 & 0.0824 & 0.0853 & 0.0888 & 0.0900 \\
\hline
\end{tabular}

Published under-five mortality rate $=0.074$.

of eligibility. The extent of birth transference is bigger in urban areas than rural areas among all children and living children. In contrast, birth dates of deceased children rural areas appear to be displaced at a higher rate than those in urban areas. Birth displacement ratio for dead children in urban areas was 98.7 percent and 81 percent for 2003 and $2008 / 09$, respectively, compared to 77.3 percent and 76.8 percent in the rural areas.

We have also checked displacement by region and indications are that there is massive displacement that varies by region. In 2008/9 only Central region and Nyanza have birth ratios greater than 90 percent among all births and living children. In 2003, it was only in Coast and Eastern regions which had a birth ratio greater than 90 percent for all births and living children. Among dead children it is only Nyanza, Nairobi, and Western region that had a birth ratio greater than 95 percent indicating no displacement. However, trends in birth ratios are inconsistent; Central region has a massive displacement of only dead children at 60 percent and 55 percent in 2003 and 2008/09, respectively. The result shows serious displacement of all children and living children for Rift Valley and Western region (birth ratio < 75.4). North Eastern region estimates are inconsistent. When birth ratios of deceased children are greater than that of living children as appears in the rural areas as well as Central, Coast, and Eastern regions, there is a possibility of negative bias in estimates of childhood mortality for the recent period (0-4year estimates).

3.4. Effect of Birth Displacement on the Measurement of UnderFive Mortality. Under-five mortality rates were reestimated for $0-1$ period, $0-2$ period, $0-3$ period, $0-4$ period, $0-5$ period, 1-5 period before the survey and the results are compared with published results. The differences should give the relative effect. The results for 2003 and 2008/09 KDHS are shown in Tables 7 and 8, respectively. The results confirm that due to displacement or birth transference underfive mortality rates for the 2008/9 data may have been underestimated due to birth displacement. However, for the 2003 data it appears that the published results may have been overestimated.

\section{Discussion}

This study assessed the quality of data collected for the estimation of under-five mortality and the credibility of the mortality decline recorded between the 2003 and 2008/09 Kenya DHSs. Our analysis showed that birth ratios for the 5 th calendar years prior to each survey were below 90 percent highlighting serious displacement of births outside the eligibility range. The findings are consistent with other studies in developing countries [7, 16]. Given our results, nearly 35 percent decline in under-five mortality in Kenya recorded in 2008/09 KDHS may not reflect the true situation.

Our study shows that birth transference among living children is bigger in urban areas than rural areas. This is unexpected since, in urban areas, data quality may be regarded with more confidence compared to rural areas [30]. Still in urban areas the result shows that birth ratios of the deceased children were greater than living children; hence there is a possibility of a negative bias in the estimates of childhood mortality for the recent period. This may explain the little progress in under-five mortality decline in urban areas compared to rural areas between 2003 and 2008/9. Our findings may not be conclusive as childhood mortality rate in the urban areas may have been inflated due to the large 
number of deaths among urban poor people. A study by Fotso et al. [31] noted that slum children exhibit much higher childhood mortality than the average urban child and, more importantly, than those in rural areas of Kenya.

Comparisons of the under-five mortality estimates derived by direct estimation from the KDHS of 2003 and 2008/09 surveys and the estimates recalculated using 0-4 period suggest the relative effect of birth displacement. It may have been that the results for the 2003 KDHS overestimated the mortality rate while the 2008/9 KDHS was underestimated due to birth displacement, thus exaggerating the rate of mortality decline.

The effect of birth displacement depends on the level of the displacement and whether or not it is related to the birth survival status. In addition, different childhood mortality indicators are affected by birth displacement differently [19]. If surviving and dead children are displaced equally, there will be little effect on mortality rate. However, if dead children are displaced more frequently, infant and child mortality and under-five mortality rates will be underestimated for the $0-4$ period. Sullivan [19] noted that under-five mortality should be underestimated in surveys with more serious birth displacement among dead children. Correspondingly, infant and child mortality and under-five mortality rates will be overestimated for the 5-9 period. The opposite will occur if surviving children are displaced more frequently.

Our analysis has a number of limitations that must be taken into consideration. However the displacement of births may not fully explain the massive decline, since we have not addressed the impact of HIV. Hallet et al. [32] reiterate that in countries with generalized epidemics of HIV infection such as Kenya mortality levels measured from standard statistics based on fertility history may be biased owing to the correlation between deaths among mothers and early childhood deaths from acquired immunodeficiency syndrome. On the other hand, it could have been that the government responses to the high and unchanging mortality after the results of the 1998 DHS and 2003 DHS are beginning to yield fruit. According to Rajarantnam et al. [33], there is compelling evidence that several low-income countries in Sub-Saharan Africa are experiencing an accelerated decline in child mortality. Substantial increases in coverage of health interventions such as immunization, insecticide-treated nets, prevention of mother-to-child transmission of HIV, or antiretroviral drugs therapy are believed to have contributed to the accelerated decline in mortality [33].

The analysis did take into consideration nonsampling errors in the birth history surveys. Nonsampling errors can potentially bias under-five mortality estimates $[7,28]$. Apart from the displacement of births, the omission of deaths and misreporting of ages and dates of birth as well as incomplete information are issues of concern. Korenromp et al. [20] explain that mothers may not report all of their births, particularly for children born long before the survey and who died at a very young age. Interviewers may fail to record all deaths in order to avoid asking potentially uncomfortable questions about the pregnancy, delivery, and feeding practices for children who have died.

\section{Conclusion}

Considering the findings of the analysis on the extent of birth displacement and its effect on the under-five mortality estimate, we conclude that the remarkable decline in the underfive mortality rate recorded in 2008/09 is a function of both overestimation of mortality in 2003 and underestimation of mortality in 2008/09. Accurate measurement of childhood mortality is vital if we are to determine the extent to which the Millennium Development Goals will be achieved. However, this simple analysis tends to raise issues on the uncertainty in the measurement of the current level of under-five mortality rate in Kenya. In interpreting under-5 mortality rates and trends from Kenya DHS, it is important to compare the result with other sources of data such as a census. Taking into consideration the limitations of the study highlighted here, there is need to conduct further research linking the observed declines in childhood mortality rate to the delivery of known effective interventions.

\section{Conflict of Interests}

The authors declare that there is no conflict of interests regarding the publication of this paper.

\section{References}

[1] K. Hill, G. Bicego, and M. Mahy, Childhood Mortality in Kenya: An Examination of Trends and Determinants in the Late 1980s to Mid-1990s, Working Paper, Johns Hopkins Population Center, 2001.

[2] NCPD, Kenya Demographic and Health Survey 1998, National Council for Population and Development; Central Bureau of Statistics; Office of the Vice-President and Ministry of Planning and National Development. Macro International Inc, Calverton, Md, USA, 1999.

[3] KNBS and ICF Macro, Kenya Demographic and Health Survey 2008-09, Kenya National Bureau of Statistics (KNBS) and ICF Macro, 2010.

[4] M. J. Hamel, K. Adazu, D. Obor et al., "A reversal in reductions of child mortality in Western Kenya, 2003-2009," American Journal of Tropical Medicine and Hygiene, vol. 85, no. 4, pp. 597605, 2011.

[5] D. D. Reidpath and P. Allotey, "Infant mortality rate as an indicator of population health," Journal of Epidemiology and Community Health, vol. 57, no. 5, pp. 344-346, 2003.

[6] J. Wilmoth, S. Zureick, V. Canudas-Romo, M. Inoue, and C. Sawyer, "A flexible two-dimensional mortality model for use in indirect estimation," Population Studies, vol. 66, no. 1, pp. 1-28, 2012.

[7] L. S. Curtis, "Assessment of the quality of the data used for the direct estimation of infant and child mortality in the DHS-II surveys," Occasional Paper 3, Macro International, Calverton, Md, USA, 1995.

[8] W. H. Mosley and L. Chen, "An analytical framework for the study of child survival in developing countries," Population and Development Review, vol. 10, pp. 25-45, 1984.

[9] D. C. Ewbank and J. N. Gribble, Effects of Health Programs on Child Mortality in Sub-Saharan Africa, National Academies Press (US), Washington, DC, USA, 1993. 
[10] N. Walker, K. Hill, and F. Zhao, "Child mortality estimation: methods used to adjust for bias due to AIDS in estimating trends in under-five mortality," PLoS Medicine, vol. 9, no. 8, Article ID e1001298, 2012.

[11] M. Mahy, Measuring Child Mortality in AIDS-Affected Countries, United Nations Population Division, New York, NY, USA, 2012, http://www.un.org/esa/population/publications/adultmort/UNICEF_Paper15.pdf.

[12] D. Cutler, A. Deaton, and A. Lleras-Muney, "The determinants of mortality," Journal of Economic Perspectives, vol. 20, no. 3, pp. 97-120, 2006.

[13] M. O. Wiens, H. Gan, C. Barigye et al., "A cohort study of morbidity, mortality and health seeking behavior following rural health center visits by children under 12 in southwestern Uganda," PLOS ONE, vol. 10, no. 1, Article ID e0118055, 2015.

[14] G. M. Zahid, "Mother's health-seeking behaviour and childhood mortality in Pakistan," Pakistan Development Review, vol. 35, part 2, no. 4, pp. 719-731, 1996.

[15] S. Becker, "Recent changes in childhood mortality in West Africa: analysis of DHS data from nine West African countries," DHS Working Papers 27, ORC Macro, Calverton, Md, USA, 2005.

[16] J. Kiersten, S. Rutstein, and P. Govindasamy, The Stall in Mortality Decline in Ghana: Further Analysis of Demographic and Health Surveys Data, ORC Macro, Calverton, Md, USA, 2005.

[17] T. W. Pullum and S. Becker, "Evidence of omission and displacement in DHS birth histories," DHS Methodological Reports 11, ICF International, Rockville, Md, USA, 2014.

[18] O. B. Ahmad, A. D. Lopez, and M. Inoue, "The decline in child mortality: a reappraisal," Bulletin of the World Health Organization, vol. 78, no. 10, pp. 1175-1191, 2000.

[19] J. Sullivan, An Assessment of the Credibility of Child Mortality Declines Estimated from DHS Mortality Rates, Working Draft, Revision 1, United Nations Children's Fund, New York, NY, USA, 2008.

[20] E. L. Korenromp, F. Arnold, B. G. Williams, B. L. Nahlen, and R. W. Snow, "Monitoring trends in under-5 mortality rates through national birth history surveys," International Journal of Epidemiology, vol. 33, no. 6, pp. 1293-1301, 2004.

[21] B. Schoumaker, "Omissions of births in DHS birth histories in sub-Saharan Africa: measurement and determinants," in Proceedings of the Annual Meeting of the Population Association of America, Washington, DC, USA, 2011.

[22] M. Garenne, "Fertility change in sub-Saharan Africa," DHS Comparative Reports 18, Macro International, Calverton, Md, USA, 2008.

[23] E. Gakidou and G. King, "Death by survey: estimating adult mortality without selection bias from sibling survival data," Demography, vol. 43, no. 3, pp. 569-585, 2006.

[24] M. Marston, B. Zaba, J. A. Salomon, H. Brahmbhatt, and D. Bagenda, "Estimating the net effect of HIV on child mortality in African populations affected by generalized HIV epidemics," Journal of Acquired Immune Deficiency Syndromes, vol. 38, no. 2, pp. 219-227, 2005.

[25] K. Hill, "Effects of HIV on methods of child mortality estimation," in Tools for Demographic Estimation, R. Dorrington, T. A. Moultrie, A. G. Hill, K. Hill, I. M. Timæus, and B. Zaba, Eds., International Union for the Scientific Study of Population, Paris, France, 2013.
[26] T. B. Hallett, S. Gregson, F. Kurwa et al., "Measuring and correcting biased child mortality statistics in countries with generalized epidemics of HIV infection," Bulletin of the World Health Organization, vol. 88, no. 10, pp. 761-768, 2010.

[27] M. Mahy, Measuring Child Mortality in AIDS-Affected Countries, United Nations Population Division, New York, NY, USA, 2003, http://www.un.org/esa/population/publications/ adultmort/UNICEF_Paper15.pdf.

[28] T. W. Pullum, "An assessment of age and date reporting in the DHS surveys 1985-2003," Methodological Reports 5, Macro International, Calverton, Md, USA, 2006.

[29] S. O. Rutstein and G. Rojas, Guide to DHS Statistics, Demographic and Health Surveys and ORC Macro, 2006.

[30] K. Johnson, M. Grant, S. Khan, Z. Moore, A. Armstrong, and Z. Sa, "Fieldwork-related factors and data quality in the demographic and health surveys program," DHS Analytical Studies 19, ICF Macro, Calverton, Md, USA, 2009.

[31] J.-C. Fotso, A. C. Ezeh, N. J. Madise, and J. Ciera, "Progress towards the child mortality millennium development goal in urban sub-Saharan Africa: the dynamics of population growth, immunization, and access to clean water," BMC Public Health, vol. 7, article 218, 2007.

[32] T. B. Hallett, S. Gregson, F. Kurwa et al., "Measuring and correcting biased child mortality statistics in countries with generalized epidemics of HIV infection," Bulletin of the World Health Organization, vol. 88, no. 10, pp. 761-768, 2010.

[33] J. K. Rajaratnam, J. R. Marcus, A. D. Flaxman et al., "Neonatal, postneonatal, childhood, and under-5 mortality for 187 countries, 1970-2010: a systematic analysis of progress towards Millennium Development Goal 4," The Lancet, vol. 375, no. 9730, pp. 1988-2008, 2010. 

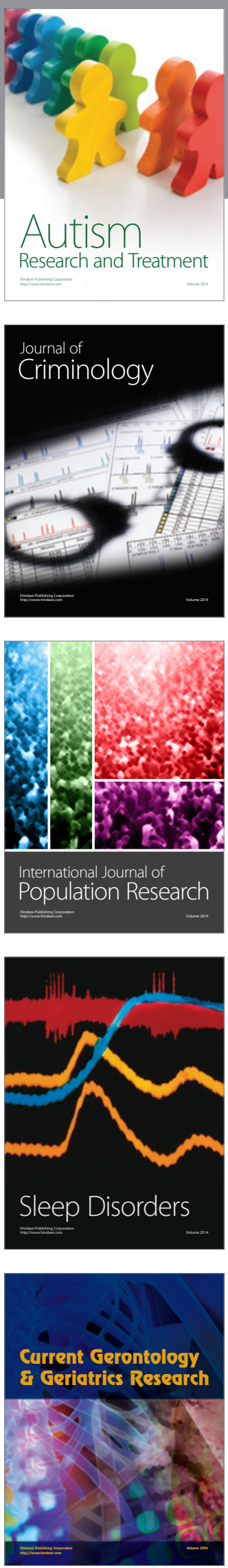
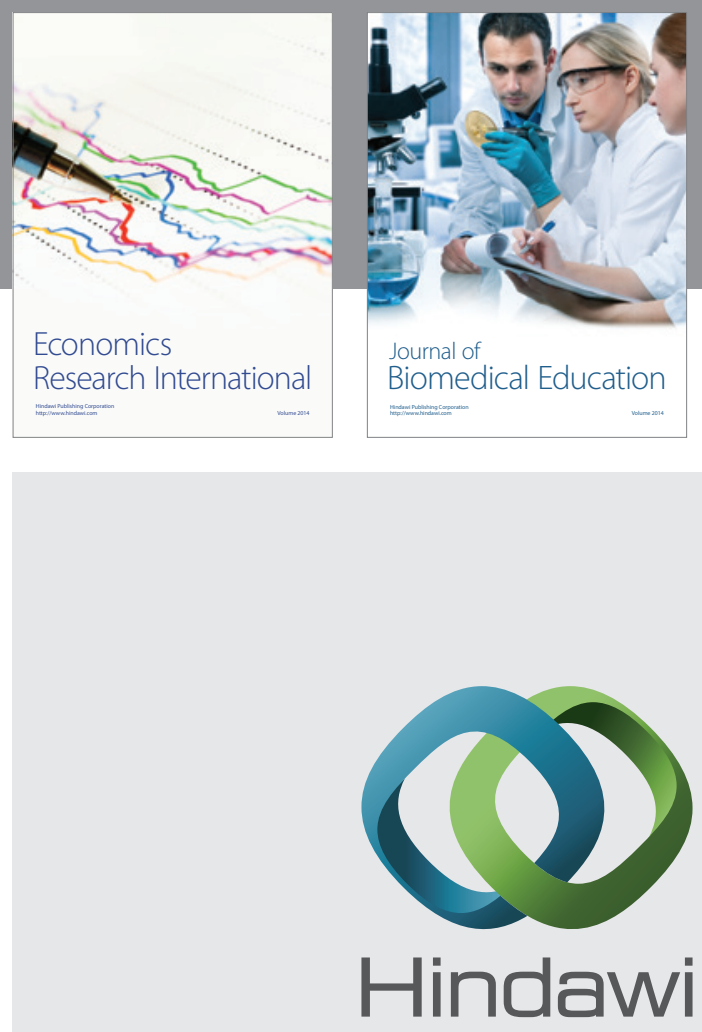

Submit your manuscripts at

http://www.hindawi.com
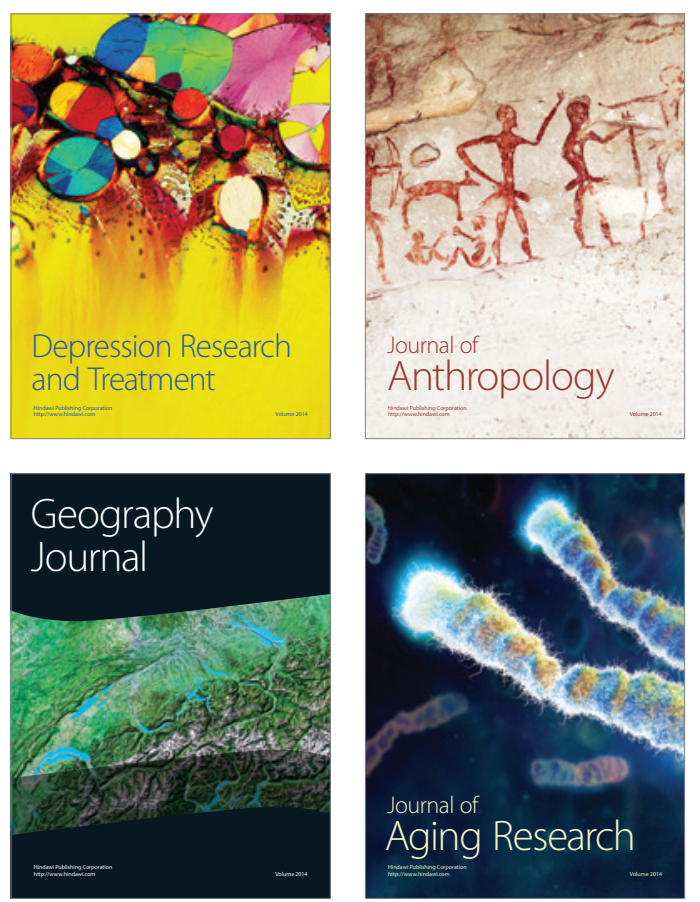
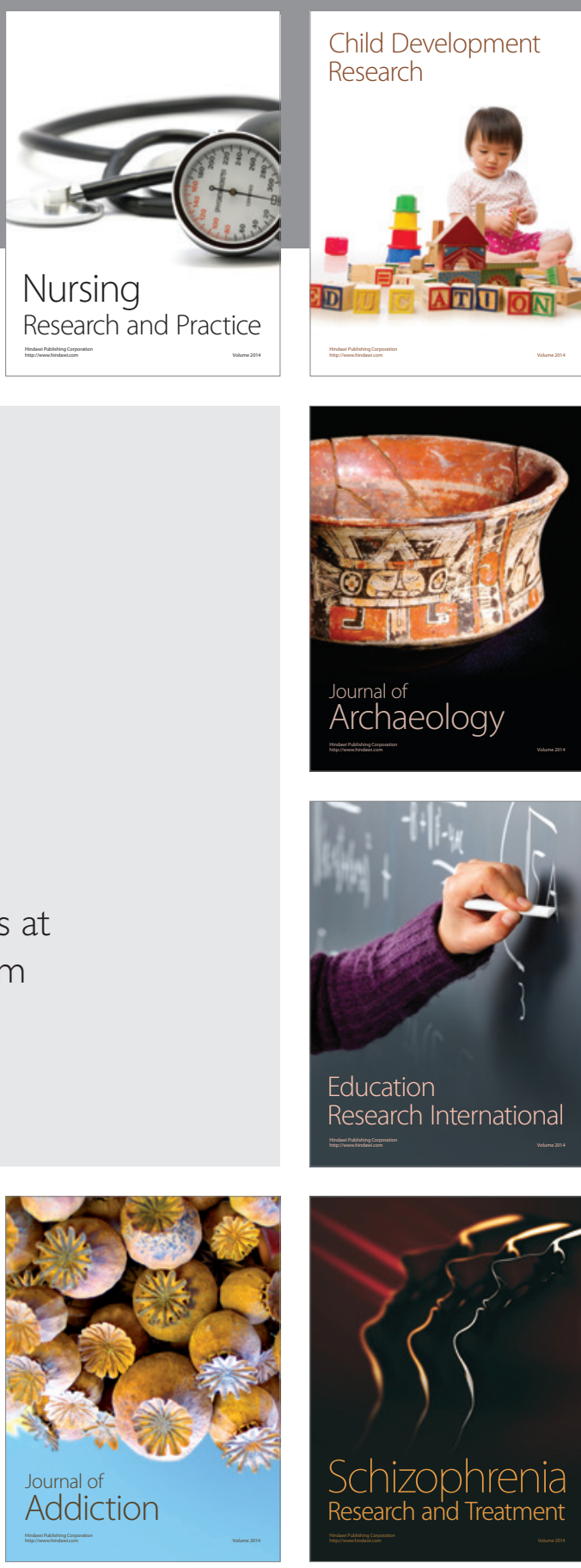

(D)
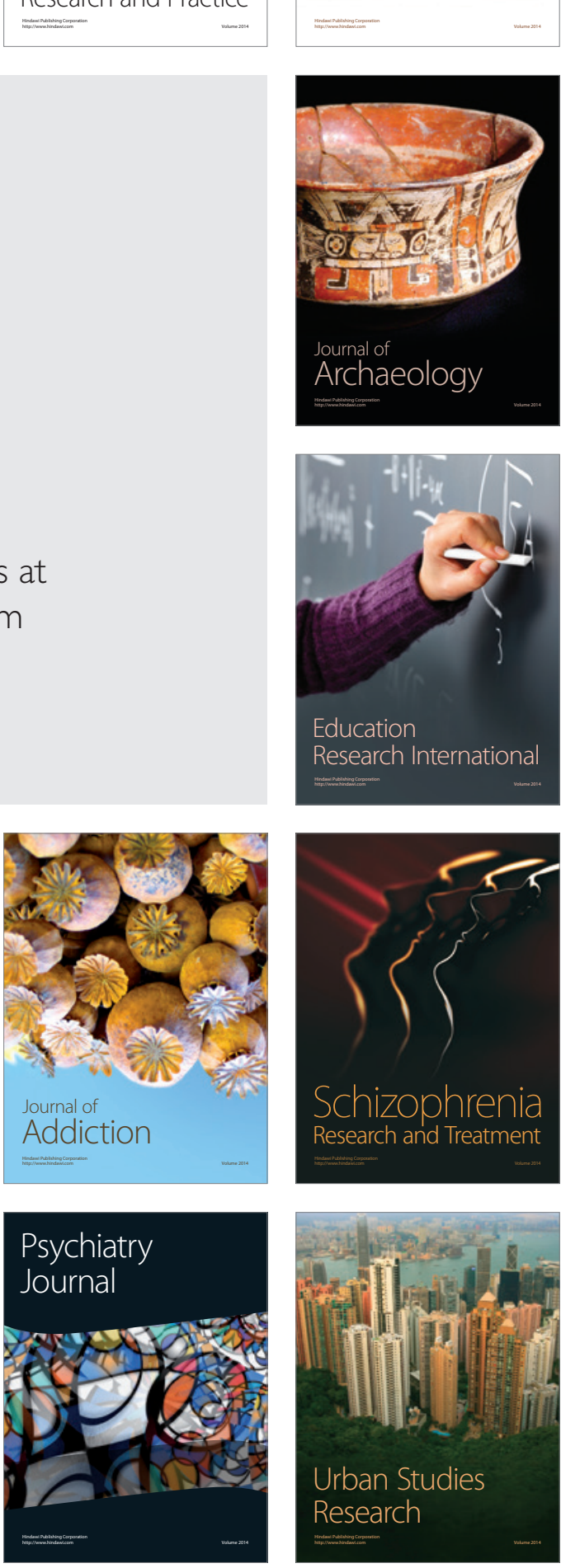